\title{
Perfil bioquímico e proteinograma do soro lácteo de cabras e vacas nos primeiros 30 dias após o parto
}

\author{
[Biochemical profile and protein concentrations of whey from goats and cows \\ in the first 30 days postpartum]
}

\section{"Artigo Científico/Scientific Article"}

\author{
Paola Fernanda Junqueira Baroza, Camila Franciosi, Daniela Gomes da Silva*, \\ André Marcos Santana, José Jurandir Fagliari
}

\begin{abstract}
Departamento de Clínica e Cirurgia Veterinária, Faculdade de Ciências Agrárias e Veterinárias (FCAV), Universidade Estadual Paulista “Júlio de Mesquita Filho” (Unesp), Jaboticabal-SP, Brasil.

*Autor para correspondência/Corresponding author: E-mail: danielafcav@yahoo.com.br
\end{abstract}

\begin{abstract}
Resumo
O objetivo do estudo foi determinar o perfil bioquímico e proteinograma do soro lácteo de cabras e vacas nos primeiros 30 dias após o parto. Foram coletadas amostras de secreção láctea de 10 cabras da raça Saanen e de 10 vacas da raça Holandesa, recém-paridas e sadias, logo após o parto (D0) e 1 (D1), 3 (D3), 5 (D5), 14 (D14) e 30 (D30) dias após o parto. Foram determinadas as concentrações de IgG, o fracionamento eletroforético em filme de agarose, as atividades das enzimas fosfatase alcalina (ALP) e gamaglutamiltransferase (GGT) e os teores de albumina, cálcio total, ferro, fósforo, magnésio e proteína total. Entre D0 e D3 ocorreram as principais alterações na composição do soro lácteo. No soro lácteo das cabras notou-se diminuição de 77,4\% e 96,1\% nos teores de IgG mensurados no D0 (3.889 mg/dL) em relação às mensurações no D1 (878 mg/dL) e D3 (152 mg/dL). No soro lácteo de vacas verificou-se diminuição de 40,0\% e 88,6\% nos teores de IgG mensurados no D0 (7.680 mg/dL) em relação àqueles obtidos no D1 (4.609 mg/dL) e D3 (874 mg/dL). Também constatou-se decréscimo gradual significativo, até D30, das concentrações de alfaglobulina, betaglobulina, gamaglobulina, proteína total, albumina, cálcio total, ferro, fósforo, magnésio e atividade das enzimas ALP e GGT. O conhecimento dos valores fisiológicos dos parâmetros bioquímicos do soro lácteo de cabras e vacas pode ser utilizado na avaliação da qualidade do colostro e transferência de imunidade passiva e no diagnóstico de enfermidades da glândula mamária como a mastite subclínica.
\end{abstract}

Palavras-chave: colostro; enzimas; IgG; minerais; leite; proteínas.

\begin{abstract}
The aim of the study was to determine the biochemical profile and protein concentrations of whey from goats and cows in the first 30 days postpartum. Milk samples from 10 Saanen goats and 10 Holstein cows, that recently gave birth and were healthy, were collected immediately after parturition (D0) and at 1 (D1), 3 (D3), 5 (D5), 14 (D14) and 30 (D30) days postpartum. The IgG concentration, electrophoretic fractionation in agarose film, enzyme activities of alkaline phosphatase (ALP) and gamma-glutamyltransferase (GGT), and albumin, total calcium, iron, phosphorus, magnesium and total protein levels were measured. Between D0 and D3 occurred the main alterations in composition of whey. In whey samples from goats, a decrease of $77.4 \%$ and $96.1 \%$ in IgG levels measured in D0 $(3,889 \mathrm{mg} / \mathrm{dL})$ were noted compared to measurements in D1 (878 $\mathrm{mg} / \mathrm{dL})$ and D3 (152 mg/dL). In whey samples from cows, a decrease of $40.0 \%$ and $88.6 \%$ in IgG levels measured in D0 (7,680 mg/dL) were observed compared to those obtained in D1 (4,609 mg/dL) and D3 (874 mg/dL). Also, a significant gradual decrease in concentrations of alpha globulin, beta globulin, gamma globulin, total protein, albumin, total calcium, iron, phosphorus, magnesium and enzyme activities of ALP and GGT until D30 was found. The knowledge of physiological values of biochemical parameters of whey from goats and cows can be used to evaluate the quality of colostrum and passive immunity transfer and in the diagnosis of mammary gland diseases such as subclinical mastitis.
\end{abstract}

Keywords: colostrum; enzymes; IgG; minerals; milk; proteins. 


\section{Introdução}

A placenta do tipo sindesmocorial dos ruminantes, que apresenta cinco camadas teciduais entre a circulação materna e a fetal, impede a passagem de anticorpos entre as duas circulações, e faz com que os ruminantes nasçam hipogamaglobulinêmicos ou agamaglobulinêmicos e dependam dos anticorpos absorvidos do colostro para aquisição de imunidade passiva (Rizzoli et al., 2006; Tizard, 2009).

O colostro, que é produzido por aproximadamente três dias, distingue-se consideravelmente do leite em relação à sua composição, propriedades físicas e funções fisiológicas. O colostro é uma secreção amarelada e viscosa que apresenta menor teor de lactose e maiores teores de gordura, sólidos totais, minerais e vitaminas, e principalmente proteína. $\mathrm{O}$ maior teor de proteína do colostro se deve principalmente à maior concentração de imunoglobulinas, que têm papel importante no estabelecimento da imunidade passiva dos recém-nascidos (Hadjipanayiotou, 1995; Barrington et al., 2001, Vilar et al., 2008).

À medida que são feitas as ordenhas ou que a cria mama diretamente na fêmea, a composição e o aspecto físico do colostro vão se aproximando aos do leite, isto é, os teores de proteína, sólidos totais, gordura, minerais e vitaminas vão diminuindo e, em contrapartida, os teores de água e lactose aumentam, até que o leite fique "limpo", o que ocorre por volta de cinco a seis dias após o parto (Campos e Miranda, 2012).

Além da composição, aspectos fisícoquímicos e microbiológicos, a análise bioquímica do colostro e do leite pode ser uma ferramenta importante para avaliação da qualidade da secreção láctea e da sanidade da glândula mamária (Fonseca e Santos, 2000; Quigley et al., 2013; Fagliari et al., 2015).

O objetivo do estudo foi determinar o perfil bioquímico e o proteinograma do soro lácteo de cabras e vacas sadias nos primeiros 30 dias após o parto.

\section{Material e Métodos}

Foram examinadas amostras de secreção láctea de 10 cabras da raça Saanen e de 10 vacas da raça Holandesa, pertencentes ao setor de Caprinocultura e Bovinocultura de Leite da FCAV/Unesp, Câmpus de Jaboticabal, recémparidas e sadias, de terceira ou quarta lactação, ordenhadas duas vezes ao dia. As cabras e vacas foram submetidas ao manejo alimentar padrão de cada setor, por meio do fornecimento diário de silagem de milho e concentrado (cabras: milho, soja, farelo de trigo, farelo de soja, farelo de algodão, núcleo leite e calcáreo; vacas: milho, farelo de soja, farelo de algodão, soja, mistura mineral e fosfato bicálcico) fornecidos ao final de cada ordenha, obedecendo as necessidades dietéticas desse estágio fisiológico. Segundo a classificação de Köppen, o município de Jaboticabal apresenta clima do tipo Aw - tropical, com temperatura média anual de $22,3^{\circ} \mathrm{C}$ e precipitação média anual de 1.416,5 mm (Rolim, 2015).

As amostras de secreção láctea, de todos os tetos de cada cabra ou vaca, foram coletadas manualmente em um único frasco plástico (totalizando um volume final de $50 \mathrm{~mL}$ ), em seis momentos distintos: logo após o parto (D0) e 1 (D1), 3 (D3), 5 (D5), 14 (D14) e 30 (D30) dias após o parto. As amostras foram obtidas após a ordenha completa dos animais.

Para a obtenção do soro lácteo foi adicionado coalho comercial (Estrella, Chr. Hansen Ind. e Com. Ltda, Valinhos, SP, Brasil) em quantidade correspondente a $5 \%$ do volume da secreção láctea. Em seguida as amostras permaneceram em banho-maria a $37^{\circ} \mathrm{C}$ durante 20 minutos, até a formação e retração do coágulo; posteriormente, foram centrifugadas a $4.500 \times \mathrm{g}$ a $4^{\circ} \mathrm{C}$, durante 15 minutos, em centrífuga refrigerada (Pizauro et al., 2014).

A concentração de IgG foi obtida pelo método de imunodifusão radial, de acordo com técnica proposta por Mancini et al. (1965), utilizando-se placas de ágar incorporadas com antissoros específicos para IgG bovina ou caprina (Vet-Rid Kit, Bethyl Laboratories, Montgomery, TX, USA), nas quais foram adicionados $5 \mu \mathrm{L}$ de amostra de soro lácteo. Para a leitura do teste foi elaborada uma curva de referência com valores de IgG previamente conhecidos.

O fracionamento eletroforético das proteínas da secreção láctea foi realizado em filme de agarose (CELMGEL ${ }^{\circledR}$, CELM, Barueri, São Paulo, Brasil), utilizando-se amostra de $0,4 \mu \mathrm{L}$ de soro lácteo. $\mathrm{O}$ exame foi conduzido em cuba horizontal (CELM) contendo tampão tris pH 9,5. Após 28 minutos de corrida a 90 volts, o filme de agarose foi corado em $200 \mathrm{~mL}$ de solução de negro de amido $0,2 \%$ (Amido Black $10 \mathrm{~B}$, CELM, Barueri, São Paulo, Brasil) durante 5 minutos. Em seguida o filme foi descorado em $200 \mathrm{~mL}$ de solução de 
ácido acético a 5\% até que o fundo se tornasse transparente, sendo então submetido à temperatura de $60^{\circ} \mathrm{C}$ até secagem completa. Após tal procedimento, foram realizadas as leituras das frações em densitômetro (CELM DS35), com comprimento de onda de $520 \mathrm{~nm}$.

Também foram determinadas as atividades das enzimas fosfatase alcalina (ALP) (método de Bowers e McComb modificado) e gamaglutamiltransferase (GGT) (método de Szasz modificado), e as concentrações de albumina (método do verde de bromocresol), cálcio total (método CPC), ferro (método de Goodwin modificado), fósforo (método de Daly e Ertingshausen modificado), magnésio (método Magon sulfonado) e proteína total (método do biureto), utilizando-se conjunto de reagentes comerciais (Labtest, Labtest Diagnóstica S.A., Lagoa Santa, Minas Gerais, Brasil); as leituras foram realizadas em espectrofotômetro semiautomático (Labquest, Labtest Diagnóstica S.A., Lagoa Santa, Minas Gerais, Brasil), em comprimentos de onda específicos para cada teste. Quando necessário, foram realizadas diluições das amostras em água destilada para que os resultados ficassem dentro do limite de linearidade do equipamento.

Os parâmetros avaliados foram submetidos à análise de variância (ANOVA) e ao teste $\mathrm{t}$ de Student para comparação entre pares de médias, ao nível de significância de 5\% (Triola, 2008), com auxílio do programa estatístico Statistical Analysis System (SAS - Versão 9.1.3).

\section{Resultados e Discussão}

As concentrações de IgG do soro lácteo de cabras da raça Saanen e vacas da raça Holandesa logo após o parto (D0) e 1 (D1), 3 (D3), 5 (D5), 14 (D14) e 30 (D30) dias após o parto, obtidas pela técnica de imunodifusão radial, são apresentadas na Tabela 1. Em ambas as espécies foi constatado decréscimo significativo da concentração desta imunoglobulina após o parto, não sendo mais detectada por esta técnica no D14 e D30 (Tabela $1)$.

A qualidade imunológica do colostro é determinada pela concentração de imunoglobulinas, principalmente $\operatorname{IgG}$ (Silper et al., 2012). O colostro é considerado de má qualidade quando possui concentração de imunoglobulinas abaixo de $21,8 \mathrm{mg} / \mathrm{mL}$, moderada qualidade quando apresenta concentração entre 22 a $49,8 \mathrm{mg} / \mathrm{mL}$ e de boa qualidade com concentrações superiores a 49,8 $\mathrm{mg} / \mathrm{mL}$ (Fleenor e Stott, 1980).

No soro lácteo das cabras foi observada diminuição de $77,4 \%$ e $96,1 \%$ nos teores de IgG mensurados no D0 em relação aos teores mensurados no D1 e D3, enquanto que no soro lácteo das vacas foi constatada diminuição de $40,0 \%$ e $88,6 \%$, respectivamente (Tabela 1). Estes dados reforçam a importância da ingestão do colostro nas primeiras 24 horas após o nascimento para assegurar adequada transferência de imunidade passiva para o ruminante recémnascido, como relatado por Fagliari et al. (1996), Feitosa et al. (2001) e Silva et al. (2007), e a importância da utilização do colostro de primeira ordenha, ou no máximo do dia seguinte ao parto, para a montagem de bancos de colostro devido à redução significativa da concentração de IgG após o parto.

Tabela 1. Média e desvio-padrão das concentrações de imunoglobulina G (IgG) (mg/dL) do soro lácteo de cabras da raça Saanen e vacas da raça Holandesa logo após o parto (D0) e 1 (D1), 3 (D3), 5 (D5), 14 (D14) e 30 (D30) dias após o parto, obtidos por imunodifusão radial.

\begin{tabular}{ccccccc}
\hline \multirow{2}{*}{ Parâmetro } & \multicolumn{7}{c}{ Dias após o parto } \\
\cline { 2 - 6 } & D0 & D1 & D3 & D5 & D14 & D30 \\
\hline IgG & & & & & \\
Cabras & $3.889 \pm 2.401 \mathrm{a}$ & $878 \pm 821 \mathrm{~b}$ & $152 \pm 70,8 \mathrm{c}$ & $163 \pm 171 \mathrm{~d}$ & nd & nd \\
Vacas & $7.680 \pm 2.762 \mathrm{a}$ & $4.609 \pm 2.291 \mathrm{~b}$ & $874 \pm 490 \mathrm{c}$ & $525 \pm 206 \mathrm{~d}$ & $\mathrm{nd}$ & $\mathrm{nd}$ \\
\hline
\end{tabular}

Letras minúsculas diferentes na mesma linha indicam diferenças entre momentos $(\mathrm{p}<0,05)$

nd: não detectado 
O fracionamento eletroforético das proteínas do soro lácteo, nesse estudo, permitiu a identificação de quatro frações proteicas (albumina, alfaglobulina, betaglobulina e gamaglobulina), e, de maneira semelhante, também foi observada a redução significativa das concentrações destas frações no soro lácteo das duas espécies entre D0 e D30, com exceção da concentração de betaglobulina no soro lácteo das vacas (Tabela 2).

A técnica de eletroforese em gel de agarose tem sido amplamente utilizada em Medicina Veterinária e, apesar de identificar o fracionamento de apenas cinco a sete grupos de proteínas, é a técnica mais disponível na rotina dos laboratórios. Devido ao significado biológico e às múltiplas funções exercidas no sistema orgânico, a avaliação das concentrações das proteínas totais e de suas frações representa um importante auxílio ao diagnóstico clínico (Godoy et al., 2006; Eckersall, 2008).

A $\alpha 1$-glicoproteína ácida, $\alpha 1$-antitripsina, ceruloplasmina, haptoglobina e amiloide A sérica representam as proteínas da fração alfa das globulinas; o fibrinogênio, proteína $\mathrm{C}$ reativa $\mathrm{e}$ amiloide A sérica integram a fração beta das globulinas (Eckersall, 2008). Essas proteínas são denominadas de proteínas de fase aguda (PFA), um grupo de proteínas sanguíneas que apresentam alterações nas suas concentrações em resposta a infecções, inflamações, traumas cirúrgicos ou estresse (Murata et al., 2004; Eckersall e Bell, 2010). Como a maioria das PFA migra para as áreas alfa e beta das globulinas, a eletroforese em gel de agarose pode ser usada para identificar os padrões de normalidade para cada espécie animal, e, assim, permitir a identificação de alterações nas concentrações das PFA nas diferentes espécies (Cerón et al., 2005; Eckersall, 2008). E como a concentração das PFA está relacionada à gravidade do distúrbio e à extensão do dano tecidual (Murata et al., 2004), a quantificação da concentração das PFA no soro lácteo pode, portanto, fornecer informações diagnósticas e prognósticas de enfermidades da glândula mamária como a mastite.

As imunoglobulinas constituem a fração gama das globulinas, as quais são absorvidas pelo intestino dos ruminantes recém-nascidos. $\mathrm{O}$ colostro perde rapidamente sua capacidade de fornecer imunidade em função do tempo transcorrido após o parto e do número de ordenhas, devido à queda da concentração de gamaglobulinas (Feitosa, 1999; Argüello et al., 2006). No soro lácteo das cabras foi observada diminuição de $78,5 \%$ e $94,3 \%$ nos teores de gamaglobulinas mensurados no D0 em relação aos teores mensurados no D1 e D3, enquanto que no soro lácteo das vacas foi constatada diminuição de $59,4 \%$ e $91,6 \%$, respectivamente (Tabela 2).

Tabela 2. Média e desvio-padrão das concentrações de albumina (g/dL), alfaglobulina (g/dL), betaglobulina (g/dL) e gamaglobulina $(\mathrm{g} / \mathrm{dL})$ do soro lácteo de cabras da raça Saanen e vacas da raça Holandesa logo após o parto (D0) e 1 (D1), 3 (D3), 5 (D5), 14 (D14) e 30 (D30) dias após o parto, obtidos pelo fracionamento eletroforético em filme de agarose.

\begin{tabular}{ccccccc}
\hline Parâmetros & \multicolumn{7}{c}{ Dias após o parto } \\
\cline { 2 - 7 } & D0 & D1 & D3 & D5 & D14 & D30 \\
\hline Albumina & & & & & \\
Cabras & $0,49 \pm 0,32 \mathrm{a}$ & $0,20 \pm 0,11 \mathrm{~b}$ & $0,17 \pm 0,07 \mathrm{~b}$ & $0,17 \pm 0,06 \mathrm{~b}$ & $0,13 \pm 0,03 \mathrm{c}$ & $0,10 \pm 0,04 \mathrm{~d}$ \\
$\quad \begin{array}{c}\text { Vacas } \\
\text { Alfaglobulina }\end{array}$ & $2,73 \pm 1,76 \mathrm{a}$ & $1,08 \pm 0,79 \mathrm{~b}$ & $0,61 \pm 0,22 \mathrm{c}$ & $0,49 \pm 0,21 \mathrm{~d}$ & $0,60 \pm 0,15 \mathrm{c}$ & $0,50 \pm 0,21 \mathrm{~d}$ \\
Cabras & $1,01 \pm 0,41 \mathrm{a}$ & $0,56 \pm 0,14 \mathrm{~b}$ & $0,52 \pm 0,09 \mathrm{~b}$ & $0,46 \pm 0,16 \mathrm{~b}$ & $0,42 \pm 0,06 \mathrm{c}$ & $0,37 \pm 0,11 \mathrm{c}$ \\
Vacas & $0,41 \pm 0,75 \mathrm{a}$ & $0,58 \pm 0,46 \mathrm{a}$ & $0,41 \pm 0,24 \mathrm{a}$ & $0,34 \pm 0,28 \mathrm{~b}$ & $0,17 \pm 0,17 \mathrm{c}$ & $0,28 \pm 0,24 \mathrm{~b}$ \\
Betaglobulina & & & & & & \\
Cabras & $3,02 \pm 1,63 \mathrm{a}$ & $1,28 \pm 0,41 \mathrm{~b}$ & $0,95 \pm 0,11 \mathrm{c}$ & $0,77 \pm 0,26 \mathrm{c}$ & $0,63 \pm 0,09 \mathrm{~d}$ & $0,54 \pm 0,18 \mathrm{e}$ \\
Vacas & $0,04 \pm 0,13 \mathrm{a}$ & $0,05 \pm 0,11 \mathrm{a}$ & $0,01 \pm 0,03 \mathrm{~b}$ & $0,02 \pm 0,04 \mathrm{~b}$ & $0,03 \pm 0,06 \mathrm{ab}$ & $0,06 \pm 0,12 \mathrm{a}$ \\
Gamaglobulina & & & & & & \\
Cabras & $6,83 \pm 3,42 \mathrm{a}$ & $1,47 \pm 1,23 \mathrm{~b}$ & $0,39 \pm 0,22 \mathrm{c}$ & $0,34 \pm 0,20 \mathrm{c}$ & $0,17 \pm 0,05 \mathrm{~d}$ & $0,13 \pm 0,07 \mathrm{~d}$ \\
Vacas & $12,6 \pm 5,31 \mathrm{a}$ & $5,11 \pm 3,00 \mathrm{~b}$ & $1,06 \pm 0,51 \mathrm{c}$ & $0,67 \pm 0,21 \mathrm{~d}$ & $0,46 \pm 0,15 \mathrm{de}$ & $0,47 \pm 0,19 \mathrm{e}$ \\
\hline
\end{tabular}

Letras minúsculas diferentes na mesma linha indicam diferenças entre momentos $(\mathrm{p}<0,05)$

Além disso, a infecção da glândula mamária pode levar a um influxo de albumina e imunoglobulinas do soro sanguíneo para o leite devido às alterações da permeabilidade vascular, aumentando as concentrações destes componentes na secreção láctea (Brito e Brito, 2001).

A análise do perfil bioquímico do soro lácteo também revelou elevada atividade das 
enzimas ALP e GGT e altas concentrações de albumina, cálcio total, ferro, fósforo, magnésio e proteína total logo após o parto (D0) (Tabela 3).

Durante o processo de colostrogênese, que inicia-se em torno de cinco semanas antes do parto e encerra-se logo após o parto, ocorre um acúmulo de proteínas e nutrientes na glândula mamária em virtude da síntese local ou pela passagem através da corrente sanguínea (Davis e Drackley, 1998; Bell et al., 2000; Andrews et al., 2008).

Mais de 40 enzimas já foram encontradas no colostro de ruminantes, sendo a GGT a mais estudada (Zanker et al., 2001). Esta enzima é produzida em grandes quantidades pelas células do epitélio de revestimento dos ductos galactóforos da glândula mamária dos ruminantes, sendo encontrada elevada concentração desta enzima no colostro (Fagliari et al., 1996; Hoffmann e Solter, 2008)

A formação do colostro inicia-se com a transferência de imunoglobulinas da circulação materna para a secreção mamária no final da gestação. Durante esta fase ocorre a transferência de IgG da circulação materna para o colostro, em razão da presença de receptores ativos e seletivos no epitélio da glândula mamária (Radostits et al., 2002; Godden, 2008) e a produção, em menores quantidades, de $\operatorname{IgA}$ e $\operatorname{IgM}$ pelos plasmócitos presentes na glândula mamária.

A atividade da enzima GGT e a concentração de proteína total colostral constituem métodos indiretos de avaliação da transferência de imunidade passiva, havendo correlação significativa das concentrações colostrais destes parâmetros com as concentrações séricas de $\mathrm{IgG}$ de ruminantes recém-nascidos que ingeriram colostro (Feitosa et al., 2010; Soares et al., 2010).

A atividade enzimática da GGT, comumente empregada para o diagnóstico de doenças hepáticas, é também recomendada como indicador de transferência de imunoglobulinas, em virtude desta enzima, estar presente em grande quantidade no colostro dos ruminantes, sendo prontamente absorvida através da barreira intestinal dos bezerros logo após o nascimento (Johnston et al., 1997; Pires Júnior et al., 2013).

O uso da proteína total como método para determinar o status de imunidade de ruminantes recém-nascidos é baseado no fato de que as imunoglobulinas são a única classe de proteína sérica cujo nível aumenta significativamente após a ingestão e absorção de colostro (Feitosa et al. 2001; Soares et al. 2010).

Entre D0 e D30 foi observada uma diminuição gradual da atividade das enzimas ALP e GGT e das concentrações de albumina, cálcio total, ferro, fósforo, magnésio e proteína total no soro lácteo de cabras e vacas (Tabela 3). Esse achado está relacionado ao fato do colostro, produzido por até dois a três dias, ter composição nutricional diferente do leite, que começa a ser produzido a partir desse momento (Tizard, 2009; Salles, 2011).

O perfil bioquímico é um procedimento valioso para o entendimento dos processos fisiopatológicos, subsídio ao diagnóstico e prognóstico e monitoramento de enfermidades (Eckersall, 2000).

Enquanto que o conhecimento dos valores fisiológicos dos parâmetros bioquímicos do soro lácteo nos primeiros dias após o parto pode ser utilizado para avaliação da qualidade do colostro e transferência de imunidade passiva, os valores destes parâmetros no leite são importantes para a identificação de alterações provocadas por enfermidades da glândula mamária como a mastite subclínica, onde, embora não ocorram mudanças clínicas visíveis no úbere ou na aparência do leite, cursam alterações na concentração de componentes da secreção láctea, decorrentes de lesões nas células produtoras de leite e alterações na permeabilidade vascular (Bastos e Birgel, 2011; Fagliari et al., 2015).

É importante ressaltar que além das enfermidades, fatores relacionados à espécie, idade, raça, fase da lactação (inicial, intermediária e final), condições climáticas, dieta dos animais, entre outros também afetam a composição da secreção láctea (Patel et al., 1993; Pizauro et al., 2014).

\section{Conclusão}

O soro lácteo dos primeiros três dias após o parto apresentou maior concentração de $\mathrm{IgG}$, alfaglobulina, betaglobulina, gamaglobulina, proteína total, albumina, cálcio total, ferro, fósforo, magnésio e maior atividade das enzimas ALP e GGT com decréscimo gradual dos valores destes parâmetros até os 30 dias após o parto.

\section{Conflito de Interesse}

Os autores declaram não existir conflitos de interesse. 
Tabela 3. Média e desvio-padrão das atividades das enzimas fosfatase alcalina - ALP (U/L) e gamaglutamiltransferase - GGT (U/L) e das concentrações de albumina (g/dL), cálcio total (mg/dL), ferro ( $\mu \mathrm{g} / \mathrm{dL})$, fósforo (mg/dL), magnésio $(\mathrm{mg} / \mathrm{dL})$ e proteína total $(\mathrm{g} / \mathrm{dL})$ do soro lácteo de cabras da raça Saanen e vacas da raça Holandesa logo após o parto (D0) e 1 (D1), 3 (D3), 5 (D5), 14 (D14) e 30 (D30) dias após o parto.

\begin{tabular}{|c|c|c|c|c|c|c|}
\hline \multirow{2}{*}{ Parâmetros } & \multicolumn{6}{|c|}{ Dias após o parto } \\
\hline & D0 & D1 & D3 & D5 & D14 & D30 \\
\hline \multicolumn{7}{|l|}{ ALP } \\
\hline Cabras & $2.069 \pm 4333 \mathrm{a}$ & $235 \pm 131 b$ & $78,0 \pm 39,5 \mathrm{c}$ & $43,9 \pm 17,9 d$ & $24,0 \pm 6,14 \mathrm{e}$ & $27,3 \pm 6,83 \mathrm{e}$ \\
\hline Vacas & $952 \pm 376 a$ & $545 \pm 327 b$ & $189 \pm 121 \mathrm{c}$ & $86,6 \pm 31,8 \mathrm{~d}$ & $129 \pm 158 \mathrm{~cd}$ & $137 \pm 140 c$ \\
\hline \multicolumn{7}{|l|}{ GGT } \\
\hline Cabras & $3.073 \pm 4.348 \mathrm{a}$ & $598 \pm 106 b$ & $451 \pm 90,8 b$ & $419 \pm 90,0 b$ & $326 \pm 107 c$ & $223 \pm 66,7 d$ \\
\hline Vacas & $25.751 \pm 13.278 \mathrm{a}$ & $17.304 \pm 10.484 b$ & $6.051 \pm 1.731 \mathrm{c}$ & $4.524 \pm 1.517 \mathrm{~d}$ & $3.703 \pm 977 \mathrm{e}$ & $3.194 \pm 701 \mathrm{e}$ \\
\hline \multicolumn{7}{|l|}{ Albumina } \\
\hline Cabras & $0,74 \pm 0,67 a$ & $0,33 \pm 0,20 b$ & $0,22 \pm 0,07 \mathrm{c}$ & $0,20 \pm 0,04 c$ & $0,17 \pm 0,06 \mathrm{~cd}$ & $0,15 \pm 0,05 d$ \\
\hline Vacas & $0,60 \pm 0,20 \mathrm{a}$ & $0,30 \pm 0,10 \mathrm{~b}$ & $0,20 \pm 0,12 \mathrm{c}$ & $0,14 \pm 0,06 \mathrm{~d}$ & $0,10 \pm 0,03 d$ & $0,10 \pm 0,05 d$ \\
\hline \multicolumn{7}{|l|}{ Cálcio Total } \\
\hline Cabras & $53,8 \pm 13,4 a$ & $46,2 \pm 8,95 b$ & $42,2 \pm 7,24 \mathrm{c}$ & $44,5 \pm 6,68 b$ & $45,0 \pm 9,36 b$ & $34,9 \pm 6,60 \mathrm{~d}$ \\
\hline Vacas & $58,8 \pm 15,0 \mathrm{a}$ & $55,3 \pm 12,9 a$ & $52,9 \pm 15,0 \mathrm{ab}$ & $54,5 \pm 10,5^{\mathrm{a}}$ & $42,1 \pm 11,1 \mathrm{c}$ & $45,2 \pm 9,78 \mathrm{c}$ \\
\hline \multicolumn{7}{|l|}{ Ferro } \\
\hline Cabras & $240 \pm 269 a$ & $42,3 \pm 42,6 b$ & $22,1 \pm 4,07 \mathrm{c}$ & $18,8 \pm 7,89 \mathrm{c}$ & $20,1 \pm 8,19 \mathrm{c}$ & $26,7 \pm 7,58 \mathrm{c}$ \\
\hline Vacas & $83,8 \pm 64,0 \mathrm{a}$ & $57,4 \pm 40,2 b$ & $44,6 \pm 27,4 b$ & $35,1 \pm 22,1 b c$ & $25,3 \pm 9,15 \mathrm{c}$ & $28,8 \pm 18,6 \mathrm{c}$ \\
\hline \multicolumn{7}{|l|}{ Fósforo } \\
\hline Cabras & $58,4 \pm 17,3 \mathrm{a}$ & $44,3 \pm 4,56 b$ & $37,4 \pm 3,20 \mathrm{c}$ & $40,7 \pm 10,0 \mathrm{c}$ & $32,1 \pm 3,71 \mathrm{c}$ & $26,1 \pm 5,99 d$ \\
\hline Vacas & $53,2 \pm 29,5 a$ & $48,3 \pm 20,3 \mathrm{ab}$ & $44,4 \pm 17,5 b$ & $41,8 \pm 18,6 b c$ & $38,3 \pm 10,1 \mathrm{c}$ & $37,3 \pm 12,7 \mathrm{c}$ \\
\hline \multicolumn{7}{|l|}{ Magnésio } \\
\hline Cabras & $22,3 \pm 8,74 a$ & $10,2 \pm 1,12 b$ & $7,69 \pm 0,98 \mathrm{c}$ & $8,16 \pm 0,66 c$ & $8,09 \pm 1,15 \mathrm{c}$ & $7,11 \pm 0,96 c$ \\
\hline Vacas & $20,0 \pm 5,28 \mathrm{a}$ & $14,6 \pm 4,83 b$ & $9,88 \pm 2,15 \mathrm{c}$ & $9,02 \pm 1,08 \mathrm{c}$ & $7,75 \pm 1,55 \mathrm{~d}$ & $8,34 \pm 1,74 d$ \\
\hline \multicolumn{7}{|l|}{ Proteína } \\
\hline Total & & & & & & \\
\hline Cabras & $10,7 \pm 5,69 a$ & $3,56 \pm 1,76 b$ & $2,03 \pm 0,35 \mathrm{c}$ & $1,91 \pm 0,37 d$ & $1,39 \pm 0,21 \mathrm{e}$ & $1,19 \pm 0,36 f$ \\
\hline Vacas & $15,8 \pm 6,55 \mathrm{a}$ & $6,82 \pm 3,50 b$ & $2,10 \pm 0,66 c$ & $1,52 \pm 0,28 \mathrm{~d}$ & $1,26 \pm 0,22 \mathrm{~d}$ & $1,23 \pm 0,25 \mathrm{~d}$ \\
\hline
\end{tabular}

Letras minúsculas diferentes na mesma linha indicam diferenças entre momentos $(\mathrm{p}<0,05)$

\section{Comitê de Ética}

O projeto de pesquisa foi aprovado pela Comissão de Ética no Uso de Animais (CEUA) da FCAV/Unesp, sob o protocolo n ${ }^{\circ} 012150-06$.

\section{Agradecimentos.}

Os autores agradecem à Fundação de Amparo à Pesquisa do Estado de São Paulo (FAPESP) pela concessão de bolsas de estudos (Processos: 2005/58914-1 e 2006/53534-9) e pelo apoio financeiro (Processo: 2006/51327-6).

\section{Referências}

Andrews, A.H.; Blowey, R.W.; Boyd, H.; Eddy, R.G. Medicina bovina: doenças e criação de bovinos. São Paulo: Roca, 2008. 1080p.

Argüello, A.; Castro, N.; Álvarez, S.; Capote, J. Effects of the number of lactations and litter size on chemical composition and physical characteristics of goat colostrum. Small Ruminant Research, 64(1-2): 53-59, 2006.

Barrington, G.M; McFadden, T.B.; Huyler, M.T.; Besser, T.E. Regulation of colostrogenesis in cattle. Livestock Production Science, 70(1-2): 95-104, 2001.

Bastos, P.A.S.; Birgel, E.H. Leite de búfalas Murrah, criadas em São Paulo (Brasil): influência da idade, fase de lactação, momento da ordenha e isolamento bacteriano na composição físico-química e celular. Revista de Educação Continuada em Medicina Veterinária e Zootecnia (CRMV-SP), 9(3): 613, 2011.

Bell, A.W.; Burhans, W.S.; Overton, T.R. Protein nutrition in late pregnancy, maternal protein reserves and lactation performance in dairy cows. Proceedings of the Nutrition Society, 59(1): 119-126, 2000.

Brito, M.A.V.P.; Brito, J.R.F. Qualidade do leite. In: Madalena, F.E.; Matos, L.L.; Holanda Júnior, E.V. Produção de leite e sociedade: uma análise crítica da cadeia do leite no Brasil. Belo Horizonte: FEPMVZ, 2001. p. 6174. 
Campos, O.F.; Miranda, J.E.C. Gado de leite: o produtor pergunta, a EMBRAPA responde. $3^{\mathrm{a}}$ ed. Brasília: EMBRAPA, 2012. 311p.

Cerón, J.J.; Eckersall, P.D.; Martínez-Subiela, S. Acute phase proteins in dogs and cats: current knowledge and future perspectives. Veterinary Clinical Pathology, 34(2): 85-99, 2005.

Davis, C.L.; Drackley, J.K. Colostrum in the development, nutrition, and management of the young calf. Ames: Iowa State University Press, 1998. p.179-206.

Eckersall, P.D. Recent advances and future prospects for the use of acute phase proteins as markers of disease in animals. Revue Médecine Vétérinaire, 151(7): 577-584, 2000.

Eckersall, P.D.; Bell, R. Acute phase proteins: Biomarkers of infection and inflammation in veterinary medicine. The Veterinary Journal, 185(1): 23-27, 2010.

Eckersall, P.D. Proteins, proteomics, and the dysproteinemias. In: Kaneko, J.J.; Harvey, J.W.; Bruss, M.L. Clinical biochemistry of domestic animals. $6^{\text {th }}$ ed. San Diego: Academic Press, 2008. pp.117-155.

Fagliari, J.J.; Oliveira, E.C.; Pegorer, M.F.; Ferrante Júnior, L.C.; Campos Filho, E. Relação entre o nível sérico de gamaglobulinas e as atividades de gamaglutamiltransferase, fosfatase alcalina e aspartato aminotransferase de bezerros recém-nascidos. Arquivo Brasileiro de Medicina Veterinária e Zootecnia, 48(2): 105-112, 1996.

Fagliari, J.J.; Sanchez, D.C.C.; Simplício, K.M.M.G.; Silva, D.G.; Santana, A.M.; Martins, A.M.C.V. Perfil bioquímico do soro lácteo de cabras com mastite clínica ou subclínica de ocorrência natural. O Biológico, 77(supl.2): 66, 2015.

Feitosa, F.L.F. Importância da transferência de imunidade passiva para a sobrevivência de bezerros neonatos. Revista de Educação Continuada em Medicina Veterinária e Zootecnia (CRMV-SP), 2(3): 17-22, 1999.

Feitosa, F.L.F.; Birgel, E.H.; Mirandola, R.M.S.; Perri, S.H.V. Diagnóstico de falha de transferência de imunidade passiva em bezerros através da determinação de proteína total e de suas frações eletroforéticas, imunoglobulinas $G$ e $\mathrm{M}$ e da atividade da gama glutamil transferase no soro sanguíneo. Ciência Rural, 31(2): 251255, 2001.

Feitosa, F.L.F.; Camargo, D.G.; Yanaka, R., Mendes, L.C.N.; Peiró, J.R.; Bovino, F.;
Lisboa, J.A.N.; Perri, S.H.V.; Gasparelli, E.R.F. Índices de falha de transferência de imunidade passiva (FTIP) em bezerros holandeses e nelores, às 24 e 48 horas de vida: valores de proteína total, de gamaglobulina, de imunoglobulina $G$ e da atividade sérica de gamaglutamiltransferase, para o diagnóstico de FTIP. Pesquisa Veterinária Brasileira, 30(8): 696-704, 2010.

Fleenor, W.A.; Stott, G.H. Hydrometer test for estimation of immunoglobulin concentration in bovine colostrum. Journal of Dairy Science, 63(6): 973-977, 1980.

Fonseca, L.F.L.; Santos, M.V. Qualidade do leite e controle de mastite. São Paulo: Lemos Editorial, 2000. 175p.

Godden, S. Colostrum management for dairy calves. The Veterinary Clinics of North America. Food Animal Practice, 24(1): 19-39, 2008.

Godoy, A.V.; Santana, A.E.; Nakage, A.P.M.; Cápua, M.L.B.; Almeida, T.L. Perfil eletroforético de proteínas séricas do sangue do cordão umbilical de cães. Ciência Rural, 36(2): 531-535, 2006.

Hadjipanayiotou, M. Composition of ewe, goat and cow milk and of colostrum and goats. Small Ruminant Research, 18(3): 255-262, 1995.

Hoffmann, W.E.; Solter, P.F. Diagnostic enzymology of domestic animals. In: Kaneko, J.J.; Harvey, J.W.; Bruss, M.L. Clinical biochemistry of domestic animals. $6^{\text {th }} \mathrm{ed}$. San Diego: Academic Press, 2008. p.351-378.

Johnston, N.A.; Parish, S.M.; Tyler, J.W.; Tillman, C.B. Evaluation of serum gammaglutammyltransferase activity as a predictor of passive transfer status in crias. Journal of the American Veterinary Medical Association, 211(9): 1165-1166, 1997.

Mancini, G.; Carbonara, A.O.; Heremans J.F. Immunochemical quantitation of antigens by single radial immunodiffusion. Imunochemistry, 2(3): 235-254, 1965.

Murata, H.; Shimada, N.; Yoshioka, M. Current research on acute phase proteins in veterinary diagnosis: an overview. The Veterinary Journal, 168(1): 28-40, 2004.

Patel, D.A.; Silva, C.V.; Sannabhadti, S.S. Sources of microbial contamination of raw milk. Indian Journal of Dairy Science, 46(2): 67-70, 1993.

Pires Júnior, J.B.; Buonora, C.R.A.; Afonso, J.A.B.; Dantas, F.R.; Pereira, A.L.L.; Vieira, A.C.S.; Mendonça, C.L. Transferência de 
imunidade passiva em bezerros oriundos de partos distócicos obtidos por cesariana. Revista Brasileira de Medicina Veterinária, 35(2): 111-116, 2013.

Pizauro, L.J.L.; Silva, D.G.; Santana, A.M.; Morais, S.M.A.; Benincasa, N.C.; Fagliari J.J. Perfil bioquímico, inclusive proteinograma, do soro lácteo de búfalas primíparas e pluríparas sadias ao longo da lactação. Pesquisa Veterinária Brasileira, 34(supl.1): 79-86, 2014.

Quigley, J.D.; Lago, A.; Chapman, C.; Erickson, P.; Polo, J. Evaluation of the Brix refractometer to estimate immunoglobulin $\mathrm{G}$ concentration in bovine colostrum. Journal of Dairy Science, 96(2): 1148-1155, 2013.

Radostits, O.M.; Gay, G.C.; Blood, D.C.; Hinchcliff, K.W. Clínica veterinária: um tratado de doenças dos bovinos, ovinos, suínos, caprinos e equinos. $9^{a}$ ed. Rio de Janeiro: Guanabara Koogan, 2002. 1737p.

Rizzoli, F.W.; Fagliari, J.J.; Silva, D.G.; Silva, S.L.; Jorge, R.L.N. Proteinograma e teores séricos de cálcio, fósforo, magnésio e ferro de bezerros recém-nascidos que mamaram colostro diretamente na vaca ou em mamadeira.

Ars Veterinaria, 22(3): 198-202, 2006.

Rolim, G.S. Dados estação convencional: dados meteorológicos mensais. Jaboticabal, SP: FCAV/UNESP. 2015. Disponível em: $<$ http://www.fcav.unesp.br/\#!/estacaoagroclim atologica/dados/estacao-convencional/>.

Acesso em: 10 mai. 2019.

Salles, M.S.V. A importância do colostro na criação de bezerras leiteiras. Pesquisa e Tecnologia, 8(2): 1-5, 2011.

Silper, B.F.; Coelho, S.G.; Madeira, M.M.F.; Ruas, J.R.M.; Lana, A.M.Q.; Reis, R.B.; Saturnino,
H.M. Avaliação da qualidade do colostro e transferência de imunidade passiva em animais mestiços Holandês Zebu. Arquivo Brasileiro de Medicina Veterinária e Zootecnia, 64(2): 281-258, 2012.

Silva, S.L.; Fagliari, J.J.; Baroza, P.F.J.; Cesco, F.T.R.S.; Jorge, R.L.N. Avaliação da imunidade passiva em caprinos recém-nascidos alimentados com colostro de cabras ou colostro de vacas. Ars Veterinaria, 23(2): 81-88, 2007.

Soares, C.M.; Simões, S.V.D.; Medeiros, J.M.A.; Riet-Correa, F.; Pereira Filho, J.M. Imunidade passiva, ingestão de colostro e mortalidade em cabritos Moxotó criados em sistemas extensivo e intensivo. Arquivo Brasileiro de Medicina Veterinária e Zootecnia, 62(3): 544-548, 2010.

Tizard, I.R. Imunologia veterinária: uma introdução. $8^{\mathrm{a}}$ ed. São Paulo: Saunders Elsevier, 2009. 587p.

Triola, M.F. Introdução à estatística. $10^{\mathrm{a}}$ ed. Rio de Janeiro: LTC, 2008. 696p.

Vilar, A.L.T.; Costa, R.G.; Souza, P.M.; Medeiros, A.N.; Queiroga, R.C.R.E; Fernandes, M.F. Efeito da ordem de parição e do período de ordenha na produção e composição do colostro e do leite de transição de cabras Saanen. Revista Brasileira de Zootecnia, 37(9): 16741678, 2008.

Zanker, I.A.; Hammon, H.M.; Blum, J.W. Activities of $\gamma$-glutamyltransferase, alkaline phosphatase and aspartate-aminotransferase in colostrum, milk and blood plasma of calves fed first colostrum at 0-2, 6-7, 12-13 and 24-25 h after birth. Journal of Veterinary Medicine. A, Physiology, Pathology, Clinical Medicine, 48(3): 179-185, 2001. 